\title{
EVIDENCE OF A NORTH-SOUTH TREND BETWEEN AUSGeoid98 AND THE AUSTRALIAN HEIGHT DATUM IN SOUTHWEST AUSTRALIA
}

\author{
W E Featherstone \\ Western Australian Centre for Geodesy, \\ Curtin University of Technology, Western Australia
}

\begin{abstract}
The AUSGeoid98 gravimetric geoid model has been compared with 48 GPS-levelling points at a $\sim 50 \mathrm{~km}$ spacing across part of the southwest of Western Australia. This is arguably the best subset of GPS-derived ellipsoidal heights in Australia with an internally estimated precision of $< \pm 9 \mathrm{~mm}$. The sprit-levelled heights were tied to the Australian Height Datum (AHD) using class C techniques [12mm-root- $\mathrm{km}$ allowable misclose]. The comparisons show that AUSGeoid98 gives a GPS height transformation to the AHD with a precision of $\sim \pm 13 \mathrm{~cm}$, which is less than reported earlier $(\sim \pm 36 \mathrm{~cm})$ for a nationwide dataset. A clear north-south trend of $\sim 0.81 \mathrm{~mm} / \mathrm{km}[\mathrm{ppm}]$ is also evident in the differences; of which approximately one-third is attributable to a north-south error in the AHD induced by dominant north-south sea surface topography effects at the nearby fixed tide gauges. After removal of this north-south trend, the standard deviation of the differences reduces to $\sim 5 \mathrm{~cm}$.
\end{abstract}

\section{INTRODUCTION}

It is common-practice to empirically validate gravimetric geoid models on land through comparisons with GPS-levelling data. Of course, this is inevitably subject to errors in the GPS and spirit levelled heights, but these are currently the only data with which to verify geoid models on land. Moreover, if the geoid models are to be subsequently used to transform GPS heights to the local vertical datum, then such an approach offers the most useful information to this majority of users. However, as geoid modelling and GPS positioning techniques continue to improve, deficiencies in local vertical datums are now becoming apparent [3].

This short note describes a comparison between the AUSGeoid98 regional gravimetric geoid model of Australia [6] and a set of 48 GPS minus Australian Height Datum (AHD [13]) 'geoid-type' heights in the southwest seismic zone (SWSZ [2]) of Western Australia. The main finding of interest here is a very clear north-south trend between AUSGeoid98 and the AHD, which is permitted because of the quality of the GPS data used. However, it remains difficult to discriminate this trend between AUSGeoid98 and the AHD.

Earlier comparisons between AUSGeoid98 and the AHD over the whole of Australia [5] indicated a general north-south trend of $\sim 0.26 \mathrm{~mm} / \mathrm{km}$ (i.e., ppm). However, this relied upon a nationwide GPS-levelling dataset that is now of questionable veracity [11]. For the present study, the internally estimated precision of the GPS-derived heights 
is $< \pm 9 \mathrm{~mm}$, which allows for a more reliable identification of the north-south trend between AUSGeoid98 and the AHD, and thus corroborates the earlier studies.

\section{DATA}

AUSGeoid98 [6] uses data from EGM96 [12], Australian land and ship-track gravity observations, a 27" regional digital elevation model, and satellite-altimeter-derived gravity anomalies in marine regions. The ship-track and altimeter gravity data were merged using least squares collocation. The residual (to EGM96) geoid heights were computed using a deterministically modified Stokes kernel in an adapted remove-compute-restore scheme. Topographical correction, downward continuation and indirect effect terms were computed approximately under the 'Moritzian' scheme, acknowledging that more sophisticated algorithms are now available.

The GPS data used in the present study were collected during May 2002 as part of a campaign to determine epoch-one coordinates for geodetic estimation of any surface deformation associated with the SWSZ belt of intra-plate [17] earthquake activity [8]. This collaborative venture involved funding and scientists from Geoscience Australia, the Western Australian Department of Land Administration (DOLA), the New Zealand Institute of Geological and Nuclear Sciences Ltd, Curtin University of Technology, and the University of Western Australia. While these GPS data were collected for geodynamic studies, they also offer a useful dataset for gravimetric geoid validation, assuming of course that the vertical geodynamic motion is small [18].

DOLA installed 48 new monuments comprising 5/8" Whitworth threads on levelled base-plates set in firm bedrock using epoxy resin and concrete. Approximately 15 of these sites were occupied simultaneously with (Trimble, Ashtech and Leica) dualfrequency GPS instruments for at least five days, coupled with a 'backbone' of five receivers tracking GPS data for the entire campaign. These data were multi-baseline processed using Bernese v.4.2 [9] with respect to permanent IGS (International GPS Service) GPS trackers at Yarragadee, Perth and Alice Springs, using IGS 'final product' orbits, and according to IGS standards $[\mathbf{1 , 8}]$.

\begin{tabular}{|c|c|c|c|}
\hline & $1 \sigma$ East $(\mathrm{mm})$ & $1 \sigma$ North $(\mathrm{mm})$ & $1 \sigma \mathrm{Up}(\mathrm{mm})$ \\
\hline Maximum & $3.4(1.4)$ & $8.3(1.5)$ & $21.8(8.8)$ \\
\hline Minimum & $0.6(0.6)$ & $0.7(0.7)$ & $3.5(3.5)$ \\
\hline Mean & $1.09(0.99)$ & $1.36(1.16)$ & $6.80(6.18)$ \\
\hline STD & $0.50(0.16)$ & $1.10(0.17)$ & $3.20(1.06)$ \\
\hline
\end{tabular}

Table 1. Descriptive statistical summary of the internally estimated precision ( $1 \sigma \mathrm{in} \mathrm{mm})$ of the GPS-derived coordinates (ITRF2000, epoch 2002.37) of the 48-point network across the SWSZ [parenthetic values exclude the two 'outliers' at SZ23 and SZ36]

The internally estimated precisions of the resulting ITRF2000 coordinates are shown in Figure 1 and summarised in Table 1 (stations SZ11 and SZ47 were not installed). Note the low precisions for stations SZ23 and SZ36 [the x axis in Figure 1 appears to be mis-registered because SZ11 is absent]. These two stations were coordinated using Leica CRS1000 instruments from the Australian GPS consortium [7], which 
caused several serious problems during the campaign due to incorrect data recording during periods of low battery power. Therefore, an auxiliary aim of this study will be to determine whether, as a corollary, AHD and AUSGeoid98 can provide a validation of the GPS vertical position solutions; cf. [14].

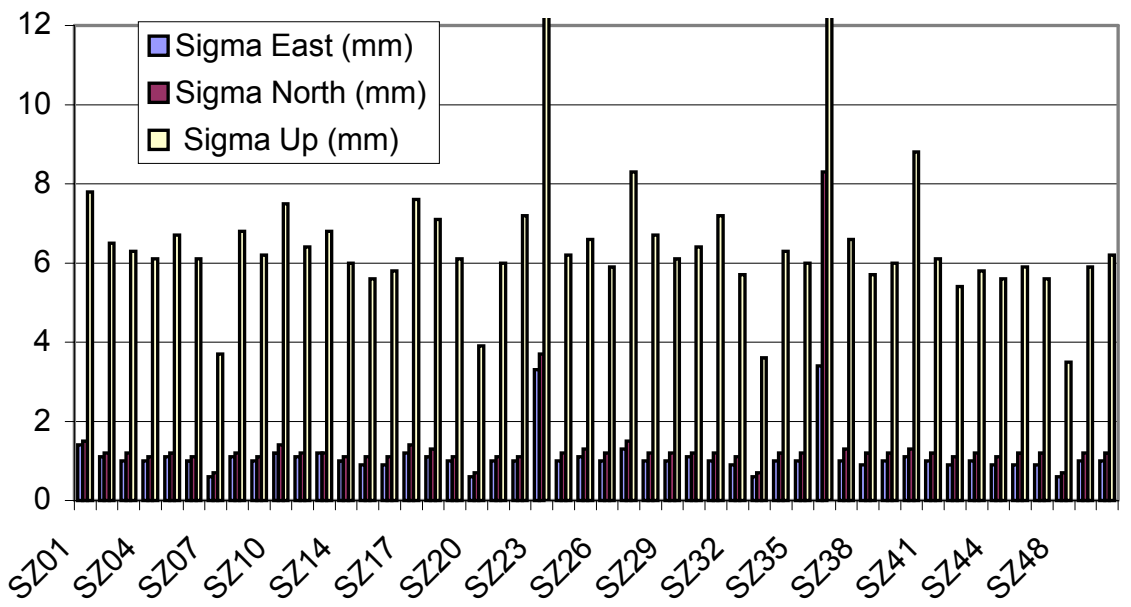

Figure 1. Internally estimated precision $(1 \sigma)$ of GPS-derived coordinates (ITRF2000 epoch 2002.37) of the 48-point network across the SWSZ (mm)

Previous GPS-levelling validations of AUSGeoid98 [5, 6] used 1,000 nationwide GPS-derived ellipsoidal heights that are now of questionable veracity [11]. Specifically, they have been compiled over a number of years during which GPS data collection and processing algorithms have matured considerably. Indeed, some earlier GPS surveys may have been tied to 'ellipsoidal heights' derived from spirit-levelled benchmarks plus earlier geoid models (i.e., $h=H+N$, where $h$ is the ellipsoidal height, $H$ is the spirit-levelled height with respect to the AHD, and $N$ is the geoid height), though this assertion cannot be verified as yet. If true, however, this is most unsatisfactory because subsequent attempts at geoid validation would only compare the new geoid model with an older one, thus not giving any validation.

DOLA geodetic surveyors sprit-levelled the $48 \mathrm{SWSZ}$ stations with respect to the AHD according to the Australian class $\mathrm{C}$ standard, which allows for a misclose of $12 \mathrm{~mm}$ per square-root-km [10]. The distance traversed from existing AHD benchmarks to the new SWSZ monuments ranged from a few tens of metres to $\sim 13 \mathrm{~km}$. The spirit levelling was conducted soon after the GPS campaign, so it is reasonably safe to assume that no vertical ground deformation (albeit small anyway [18]) has occurred between the GPS and spirit-levelling observations.

The AHD is widely acknowledged to contain distortions of $\sim 1.5 \mathrm{~m}[3,12]$, with a dominant north-south trend, which is attributed to the effects of sea surface topography on the 30 tide gauges fixed to mean sea level in the 1971 adjustment; e.g., [4]. Therefore, the major error in the levelled heights probably stems from the definition of the AHD and subsequent spirit levelling data. The difficulty of estimating errors from allowable miscloses is well known, so a "hand-waving argument" (i.e., without scientific or numerical rigour) is used to estimate the AHD height errors as $\sim 20 \mathrm{~mm}$ over the SWSZ, excluding the systematic errors in the AHD. 


\section{METHODS, RESULTS AND DISCUSSION}

Gravimetric geoid heights were computed at the ITRF2000 coordinates of the 48 stations (Appendix A) using on-line facilities that interpolate from precomputed geoid grids. AUSGeoid98 was bi-cubically interpolated via http:/www.auslig.gov.au/geodesy/aus geoid/nvalcomp.htm. EGM96 was spline interpolated from http://164.214.2.59/GandG/ egm96/intpt.htm. These geoid heights were then subtracted from the GPS-levellingderived 'geoid-type' heights, and summarised in Table 2.

\begin{tabular}{|c|c|c|c|c|}
\hline & Maximum & Minimum & Mean & STD \\
\hline GPS-AHD minus & 0.196 & -0.277 & -0.010 & \pm 0.129 \\
AUSGeoid98 & $(0.196)$ & $(-0.277)$ & $(-0.009)$ & $( \pm 0.132)$ \\
\hline GPS-AHD & 1.175 & -0.211 & 0.512 & \pm 0.283 \\
minus EGM96 & $(1.175)$ & $(-0.211)$ & $(0.512)$ & $( \pm 0.283)$ \\
\hline
\end{tabular}

Table 2. Descriptive statistical summary (in $\mathrm{m}$ ) of the differences between the 48 SWSZ GPS-AHD heights and AUSGeoid98 and EGM96 (parenthetic values exclude the two 'outliers' at SZ23 and SZ36)

The larger mean value of the differences between the GPS-levelling and EGM96 geoid heights in Table 2 is due to the different zero-degree geoid terms. The zero-degree term in EGM96 is computed from the difference in mass and potential between it and the WGS84 normal ellipsoid, and its value has been determined as $-53 \mathrm{~cm} \mathrm{[12].} \mathrm{The} \mathrm{zero-}$ degree term in AUSGeoid98 was computed from the mean difference from a nation-wide set of GPS-levelling data, and its value has been determined as $-94 \mathrm{~cm} \mathrm{[6].} \mathrm{As} \mathrm{such,} \mathrm{the}$ standard deviation (and trends, described later) should be interpreted as the more reliable statistics.

From Table 2, there is no evidence that the two 'outliers' (i.e., in terms of the larger internal error estimates; Figure 1) in the processed GPS data significantly degrade the comparisons. Therefore, it can be assumed that the GPS data processing has probably fixed the correct ambiguities for these stations, though the noise at each is higher. Accordingly, it could be argued that the use of GPS and levelling data provides a useful external check on GPS height solutions; cf. [14].

Figures 2, 3 and 4 show the (GPS-AHD minus AUSGeoid98) differences plotted as functions of ITRF2000 latitude, ITRF2000 longitude and AHD height, respectively. Figures 5, 6 and 7 show the same for EGM96. There is a clear $\left(\mathrm{R}^{2}=0.82\right.$; i.e., goodness of fit) north-south trend of $\sim 0.81 \mathrm{~mm} / \mathrm{km}$ (ppm) between the AHD and AUSGeoid98 (Figure 2), whereas there is no appreciable east-west trend (Figure 3) or elevationdependent trend (Figure 4). The trends for EGM96 are far less clear (Figures 5, 6 and 7), simply because of the poorer overall agreement with the GPS levelling data (Table 1), but the north-south trend of $\sim 0.95 \mathrm{~mm} / \mathrm{km}$ for EGM96 is the 'better' defined $\left(\mathrm{R}^{2}=0.23\right)$. The small elevation-dependent trend in Figures 4 and 7 is due to the AHD heights increasing southwards in the study area. 


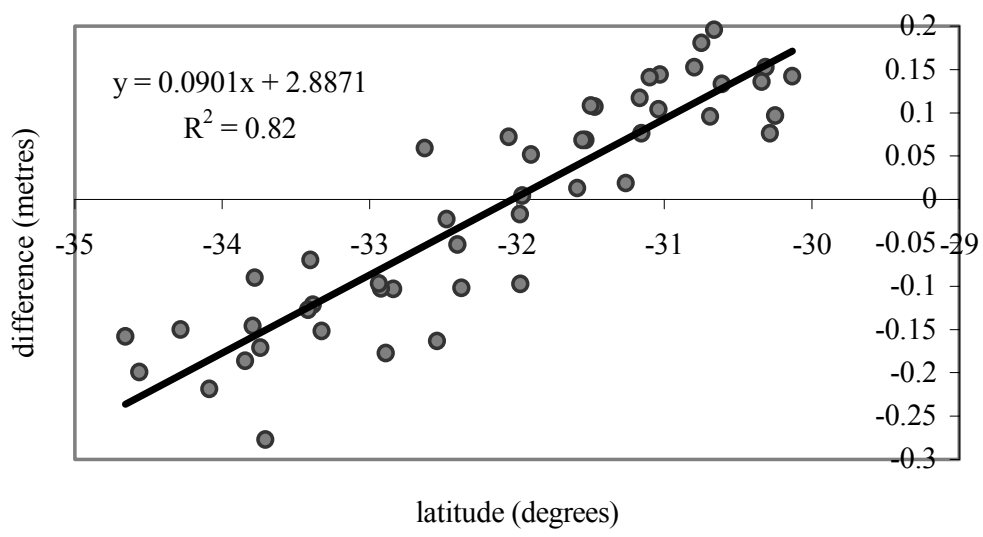

Figure 2. Differences (in m) between the 48 SWSZ GPS-AHD heights and AUSGeoid98 as a function of ITRF2000 latitude

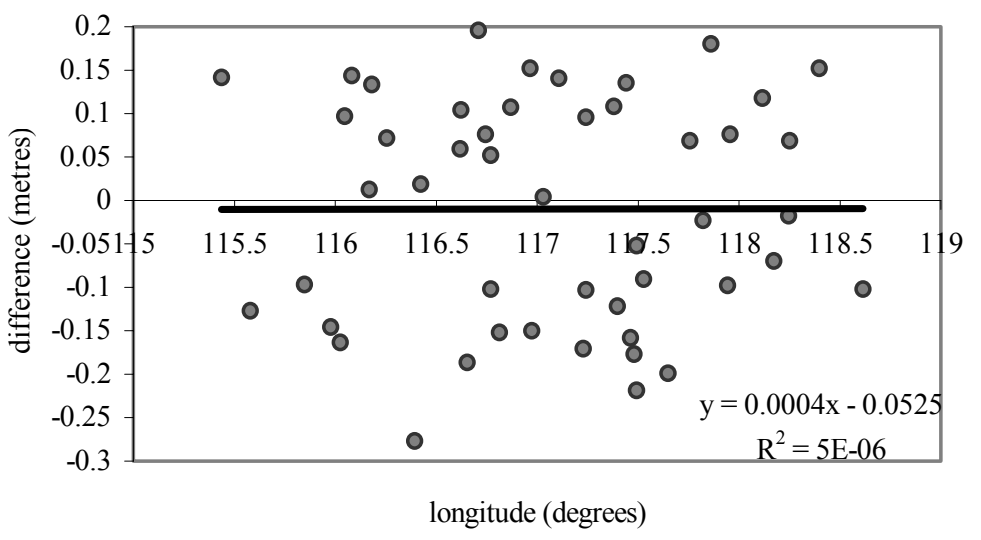

Figure 3. Differences (in $m$ ) between the 48 SWSZ GPS-AHD heights and AUSGeoid98 as a function of ITRF2000 longitude

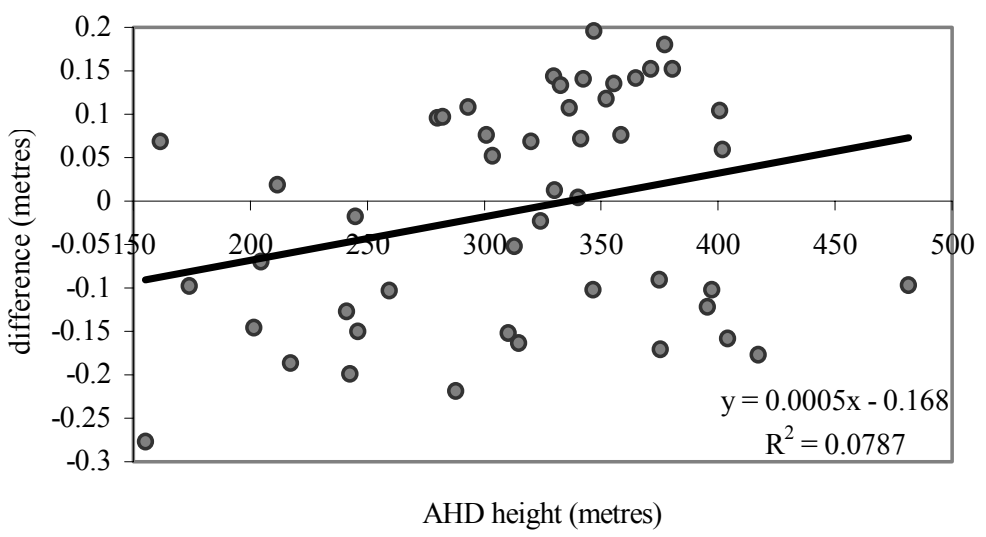

Figure 4. Differences (in $\mathrm{m}$ ) between the 48 SWSZ GPS-AHD heights and AUSGeoid98 as a function of AHD height 


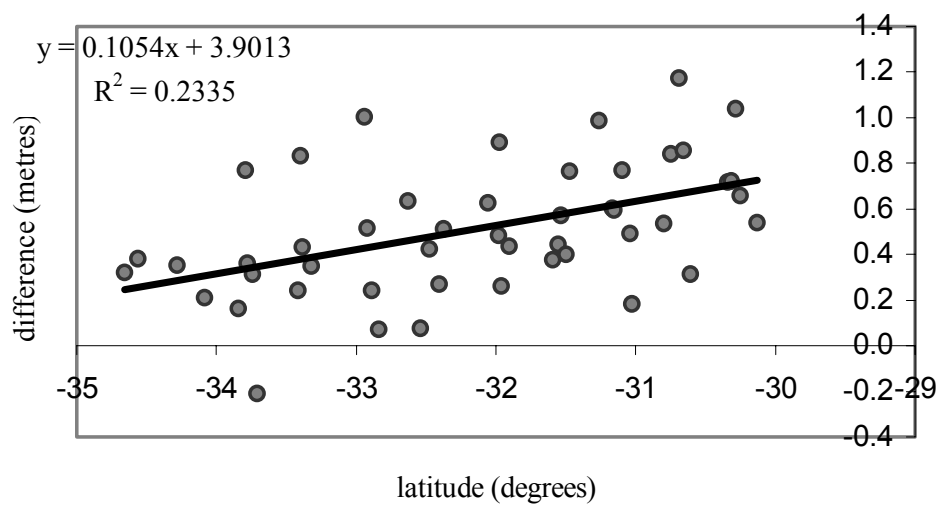

Figure 5. Differences (in $\mathrm{m}$ ) between the 48 SWSZ GPS-AHD heights and EGM96 as a function of ITRF2000 latitude

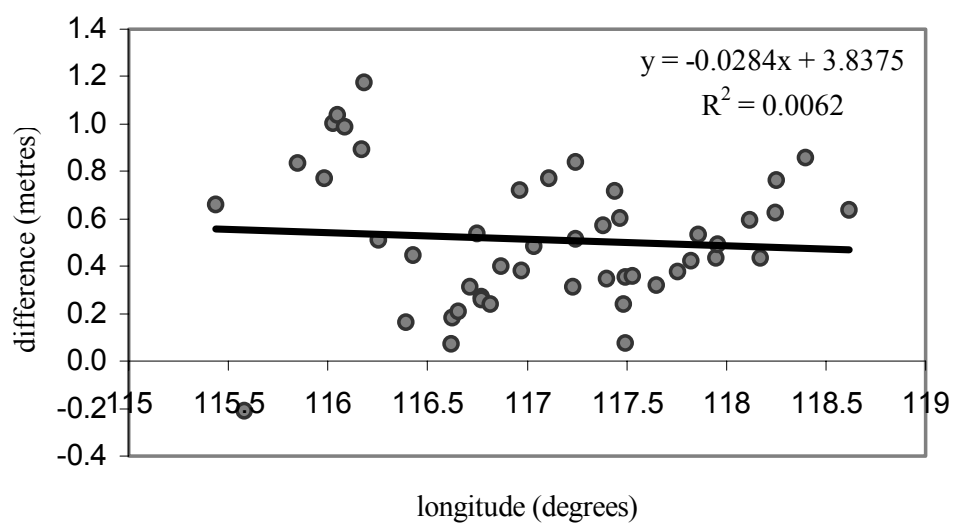

Figure 6. Differences (in $\mathrm{m}$ ) between the 48 SWSZ GPS-AHD heights and EGM96 as a function of ITRF2000 longitude

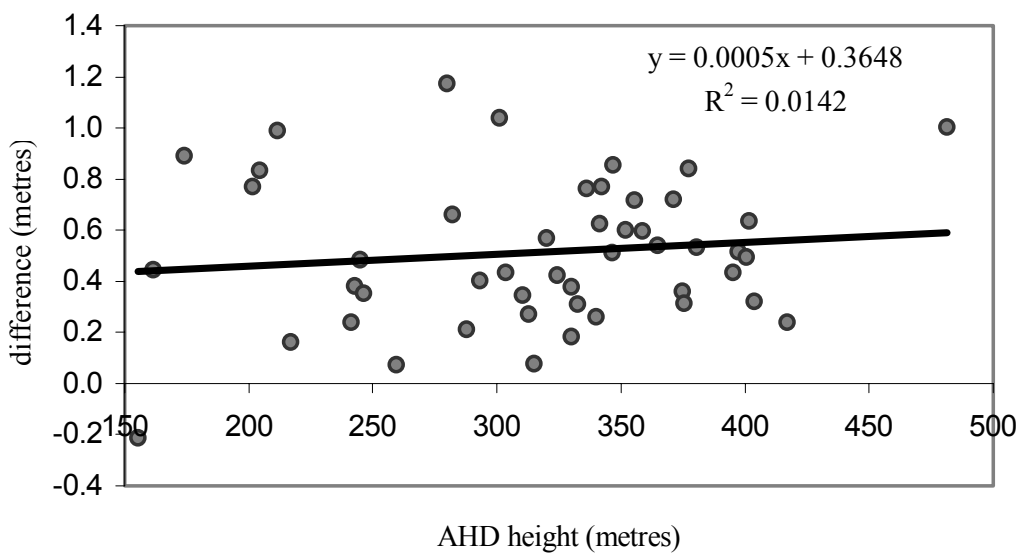

Figure 7. Differences (in $m$ ) between the 48 SWSZ GPS-AHD heights and EGM96 as a function of AHD height 
Comparing Figures 2, 3 and 4 with Figures 5, 6 and 7 and the results in Table 1 show that AUSGeoid98 improves upon EGM96 (as is to be expected because of the inclusion of additional data to reduce the omission error) by reducing the standard deviation and the magnitude of the trends. However, the addition of regional gravity data cannot completely correct long-wavelength errors (the commission error) in the global geopotential model [16]. As such, the remaining $\sim 0.81 \mathrm{~mm} / \mathrm{km}$ north-south trend may be due to propagation of a long-wavelength error in EGM96 into AUSGeoid98.

This clear north-south trend concurs with previous studies by this author $[4,5,6]$, but is more conclusive because of the good quality GPS data used in this study. Importantly, this only shows that the differences (assumed to be errors) are in one or all of the AHD, AUSGeoid98 and EGM96. However, these cannot be separated because of the correlations, lack of redundancy and likely errors in the AHD, AUSGeoid98 and EGM96. For instance, a $\sim 0.81-0.95 \mathrm{~mm} / \mathrm{km}$ tilt in one or all of the AHD, AUSGeoid98 and EGM96 is entirely plausible.

Figure 8 shows contours of the differences between the AHD and AUSGeoid98, computed using a tensioned spline interpolation [15]. The north-south trend, which is clear in Figure 2, is not so clear in Figure 8, thus showing the usefulness of a simple linear regression.

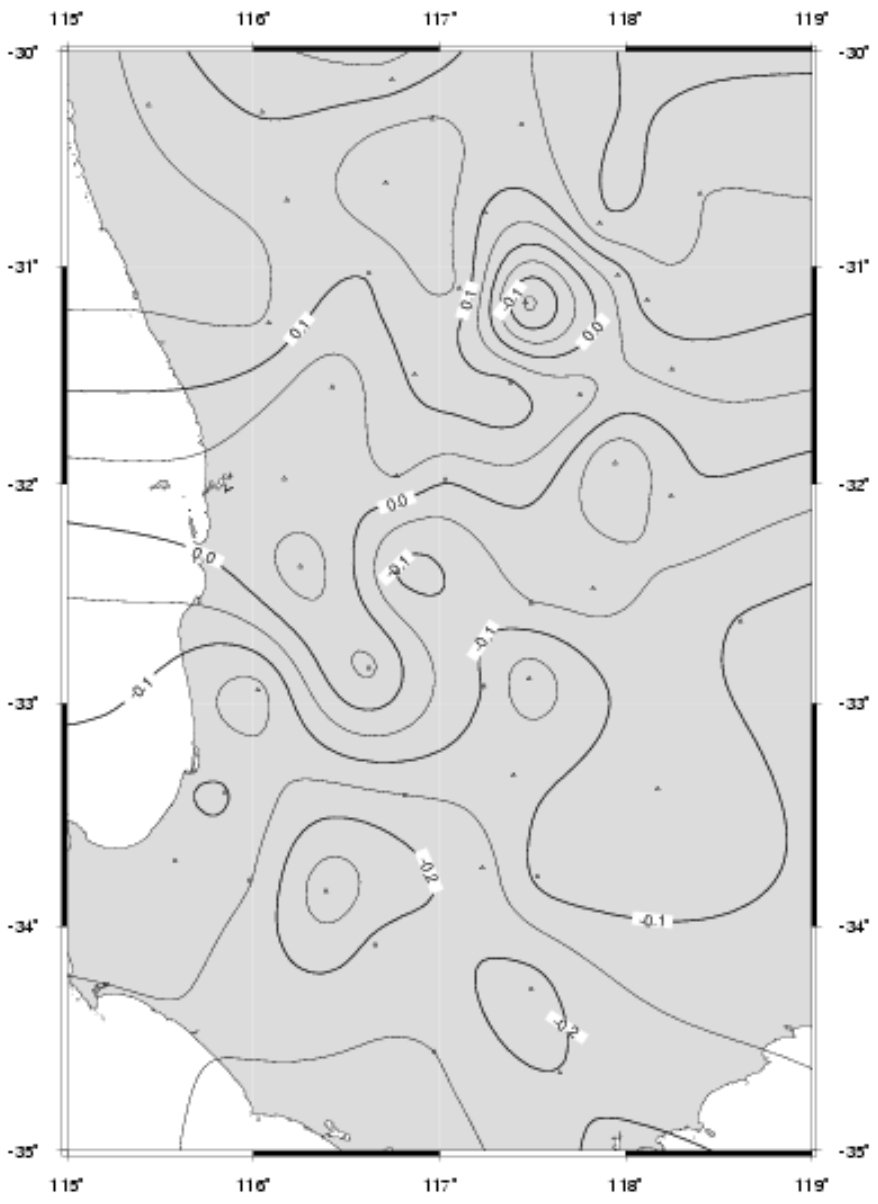

Figure 8. Contours (in m) of differences between the AHD and AUSGeoid98 (no trend removed) 
Thus far, the systematic errors in the AHD have been omitted from the analysis and discussion. As stated, the $\sim 1.5 \mathrm{~m}$ distortions in the AHD are dominated by a northsouth trend, which is attributed to unmodelled sea surface topography (SST) effects on the tide gauges fixed in the realisation of the AHD. [4] shows that published SST models indicate a dominance in the north-south direction. Therefore, it is reasonable to expect that this will introduce a north-south distortion in the AHD.

In order to substantiate this, contours of the differences between the free-and fixed-network adjustments of the AHD ([13], Annex D) were 'consulted', and were used to estimate a north-south tilt of $\sim 0.55 \mathrm{~mm} / \mathrm{km}$ in the AHD across the SWSZ. Removing this estimate from the trend computed from Figure 2 indicates a north-south tilt of $\sim 0.26$ $\mathrm{mm} / \mathrm{km}$ in AUSGeoid98, and a tilt of $\sim 0.40 \mathrm{~mm} / \mathrm{km}$ in EGM96. However, the many conditions outlined earlier, notably the inseparability problem, mean that these values must be treated with great caution.

Finally, the $\sim 0.81 \mathrm{~mm} / \mathrm{km}$ north-south trend between the AHD and AUSGeoid98 (Figure 2) was removed from the differences, and the descriptive statistics recomputed. Table 2 shows that the use of GPS in conjunction with the north-south tilted AUSGeoid98 model will yield AHD heights to a precision of $\sim 5 \mathrm{~cm}$ in the SWSZ. This value is commensurate with results in many other parts of the world.

\begin{tabular}{|c|c|c|c|c|}
\hline & Maximum & Minimum & Mean & STD \\
\hline $\begin{array}{c}\text { GPS-AHD minus } \\
\text { tilted AUSGeoid98 }\end{array}$ & 117 & -127 & 0 & \pm 55 \\
\hline
\end{tabular}

Table 2. Descriptive statistical summary (in $\mathrm{mm}$ ) of the differences between the 48 SWSZ GPS-AHD heights and the tilted AUSGeoid98

\section{SUMMARY AND CONCLUSIONS}

This short note has presented a simple validation of the AUSGeoid98 regional gravimetric geoid model of Australia using a high-quality GPS dataset across part of southwestern Western Australia. It confirms earlier indications that there is a clear north-south trend between the AHD and AUSGeoid98, but the source of this trend cannot yet be reliably separated. Simple inspection of the free- versus fixed-network adjustments of the AHD in the study area suggests that fixing local tide gauges to mean sea level can account for approximately one-third of the observed trend. Before the trend was removed, the standard deviation of agreement was $\sim 13 \mathrm{~cm}$, which reduced to $\sim 5 \mathrm{~cm}$ after trend removal. These values are more optimistic than previous studies (e.g., $\sim 36 \mathrm{~cm}$; [6]), which are attributed, in part, to the use of significantly improved GPS data for this study.

\section{Acknowledgements}

I would like to thank John Dawson (Geoscience Australia) for providing the processed GPS results, and Linda Morgan (DOLA) for providing the spirit-levelling data. This research has been supported financially by Australian Research Council grant DP0211827, Geoscience Australia, the Western Australian Department of Land Administration, the New Zealand Institute of Geological and Nuclear Sciences Ltd, Curtin University of Technology, and the University of Western Australia. Thanks are also extended to the two anonymous reviewers and editor of this manuscript. 


\section{REFERENCES}

1. Dawson, J. (2002) South West Seismic Zone 2002: GPS Analysis. Technical Report, National Mapping Division, Geoscience Australia, Canberra, Australia, 68 pp.

2. Doyle, H.A. (1977) Seismicity and structure in Australia, Royal Society of New Zealand Bulletin 9: 149-152.

3. Featherstone, W.E. (1998) Do we need a gravimetric geoid or a model of the base of the Australian Height Datum to transform GPS heights? The Australian Surveyor 43: 273-280.

4. Featherstone, W.E. (2002) Prospects for the Australian Height Datum and geoid model, in: Adam, J. and Schwarz, K.P (eds) Vistas for Geodesy in the New Millennium, Springer, Berlin, 96-101.

5. Featherstone, W.E. and W. Guo (2001) A spatial evaluation of the precision of AUSGeoid98 versus AUSGeoid93 using GPS and levelling data, Geomatics Research Australasia 74: 75102.

6. Featherstone, W.E., J.F. Kirby, A.H.W. Kearsley, J.R. Gilliland, G.M. Johnston, J. Steed, R. Forsberg, M.G. Sideris (2001) The AUSGeoid98 geoid model of Australia: data treatment, computations and comparisons with GPS-levelling data, Journal of Geodesy 75: 313-330.

7. Featherstone, W.E., M.P. Stewart, C. Rizos, S. Han, R. Coleman, P. Tregoning and P.J. Morgan (2000) A new facility to enhance Australian GPS-geodetic research, The Australian Surveyor, 45(1): 20-30.

8. Featherstone, W.E., N.T. Penna, M. Leonard, D. Clark, J. Dawson, M.C. Dentith, D. Darby and R. McCarthy (2003) GPS-geodetic deformation monitoring of the southwest seismic zone of Western Australia: epoch-one, Journal of the Royal Society of Western Australia (submitted).

9. Hugentobler, U., S. Schaer and P. Fridez (eds) (200) Bernese GPS Software Version 4.2. University of Berne, Switzerland, 513 pp.

10. ICSM (2002) Standards and Practices for Control Surveys (version 1.5), Inter-Governmental Committee on Surveying and Mapping, Canberra, [http://www.icsm.gov.au/icsm/publications/sp1/sp1.htm].

11. Johnston, G.M. and G.C. Luton (2001) GPS and the Australian Height Datum, in: Kubik, K. C. Rizos and W.E. Featherstone (eds) Proceedings of the 5th International Symposium on Satellite Navigation Technology and Applications, Canberra, July [CD-ROM].

12. Lemoine, F.G., Kenyon, S.C., Factor, J.K., Trimmer, R.G., Pavlis, N.K., Chinn, D.S., Cox, C.M., Klosko, S.M., Luthcke, S.B., Torrence, M.H., Wang, Y.M., Williamson, R.G., Pavlis, E.C., Rapp, R.H. and Olson, T.R., 1998. The development of the joint NASA GSFC and the National Imagery and Mapping Agency (NIMA) geopotential model EGM96, NASA/TP1998-206861, National Aeronautics and Space Administration, Washington, 575 pp.

13. Roelse, A., H.W. Granger and J.W. Graham (1971) The adjustment of the Australian levelling survey 1970-71, Report 12, Division of National Mapping, Canberra, 81 pp.

14. Sideris M.G., A. Mainville and R. Forsberg (1992) Geoid testing using GPS and levelling (or GPS testing using levelling and the geoid?), Australian Journal of Geodesy Photogrammetry and Surveying 57: 62-77.

15. Smith, W.H.F. and P. Wessel (1990) Gridding with continuous curvature splines in tension, Geophysics 55: 293-305

16. Vaníček, P., Featherstone, W.E. (1998) Performance of three types of Stokes's kernel in the combined solution for the geoid, Journal of Geodesy 72: 684-697 
17. Wdowinski, S. (1998) A theory of intraplate tectonics, Journal of Geophysical Research 103(B3): 5037-5059.

18. Wellman, P. and R. Tracey (1987) South-west Seismic Zone of Western Australia: measurement of vertical ground movements by repeat levelling and gravity surveys, BMR Journal of Geology and Geophysics 10:225-232.

\section{Appendix A: SWSZ GPS-levelling data}

\begin{tabular}{|c|c|c|c|}
\hline $\begin{array}{c}\text { Latitude } \\
\text { degrees) }\end{array}$ & $\begin{array}{c}\text { Longitude } \\
\text { (degrees) }\end{array}$ & $\begin{array}{c}\text { Ellipsoidal } \\
\text { height }(\mathrm{m})\end{array}$ & $\begin{array}{c}\text { AHD } \\
\text { height }(\mathrm{m})\end{array}$ \\
\hline-30.2491617 & 115.438471 & 252.0994 & 282.230 \\
\hline-30.282882 & 116.047472 & 273.5354 & 300.856 \\
\hline-30.1316919 & 116.746192 & 340.3401 & 364.691 \\
\hline-30.3133847 & 116.963217 & 346.8963 & 371.104 \\
\hline-30.3398711 & 117.441334 & 331.7438 & 355.566 \\
\hline-30.6908414 & 116.180941 & 252.8395 & 279.965 \\
\hline-30.6106898 & 116.710647 & 307.2231 & 332.561 \\
\hline-30.7498066 & 117.243825 & 352.5656 & 377.236 \\
\hline-30.7978249 & 117.860203 & 356.1396 & 380.395 \\
\hline-30.6620563 & 118.399419 & 323.1680 & 346.911 \\
\hline-31.2604024 & 116.083051 & 182.5188 & 211.530 \\
\hline-31.0302283 & 116.621416 & 303.6589 & 329.846 \\
\hline-31.0994332 & 117.10764 & 316.6748 & 342.234 \\
\hline-31.0401382 & 117.957368 & 375.7898 & 400.476 \\
\hline-31.1542331 & 118.115965 & 333.6465 & 358.480 \\
\hline-31.5553041 & 116.425922 & 134.0393 & 161.614 \\
\hline-31.4978989 & 116.868133 & 266.6029 & 293.241 \\
\hline-31.5352052 & 117.382447 & 293.6077 & 319.917 \\
\hline-31.5900978 & 117.755766 & 303.8279 & 329.960 \\
\hline-31.4737531 & 118.249463 & 311.0133 & 336.229 \\
\hline-31.9749827 & 116.166668 & 144.7364 & 173.835 \\
\hline-31.9647709 & 116.771438 & 313.0803 & 340.019 \\
\hline-31.9800179 & 117.032417 & 218.3307 & 244.935 \\
\hline-31.9039321 & 117.9455 & 277.5698 & 303.685 \\
\hline & & & \\
\hline
\end{tabular}

\begin{tabular}{|c|c|c|c|}
\hline $\begin{array}{c}\text { Latitude } \\
\text { degrees) }\end{array}$ & $\begin{array}{c}\text { Longitude } \\
\text { degrees) }\end{array}$ & $\begin{array}{c}\text { Ellipsoidal } \\
\text { height }(\mathrm{m})\end{array}$ & $\begin{array}{c}\text { AHD } \\
\text { height }(\mathrm{m})\end{array}$ \\
\hline-32.0555522 & 118.245806 & 315.6509 & 341.395 \\
\hline-32.37691 & 116.25396 & 318.0106 & 346.348 \\
\hline-32.403708 & 116.768889 & 286.1540 & 312.962 \\
\hline-32.5429589 & 117.49173 & 288.2168 & 314.890 \\
\hline-32.4774548 & 117.824038 & 298.0209 & 324.217 \\
\hline-32.937729 & 116.024241 & 452.1572 & 481.392 \\
\hline-32.8375496 & 116.620429 & 232.2296 & 259.337 \\
\hline-32.9209674 & 117.240981 & 370.7064 & 397.160 \\
\hline-32.8879441 & 117.481825 & 390.5158 & 417.044 \\
\hline-32.6262863 & 118.616647 & 375.3281 & 401.732 \\
\hline-33.4009708 & 115.847875 & 173.795 & 204.411 \\
\hline-33.4162649 & 116.814997 & 213.9165 & 241.175 \\
\hline-33.3247531 & 117.398451 & 283.4584 & 310.311 \\
\hline-33.384376 & 118.172151 & 368.2373 & 395.294 \\
\hline-33.7073268 & 115.580636 & 122.5700 & 155.281 \\
\hline-33.8441164 & 116.391983 & 188.6789 & 217.066 \\
\hline-33.7398525 & 117.230842 & 347.9799 & 375.285 \\
\hline-33.7790254 & 117.527751 & 347.8387 & 374.858 \\
\hline-33.7941048 & 115.979122 & 171.6461 & 201.446 \\
\hline-34.0854923 & 116.655716 & 259.3983 & 287.767 \\
\hline-34.2813289 & 117.493036 & 217.6259 & 246.182 \\
\hline-34.5600101 & 116.972252 & 212.3189 & 242.746 \\
\hline-34.6551835 & 117.647355 & 373.3640 & 403.864 \\
\hline-31.1681761 & 117.464577 & 326.5092 & 351.908 \\
\hline
\end{tabular}

